\section{Estudo \\ Debate}

em CAStão

Plamejamento
Revista Estudo \& Debate, Lajeado, v. 25, n. 1, 2018. ISSN 1983-036X

DOI: http://dx.doi.org/10.22410/issn.1983-036X.v25ila2018.1386

\title{
ANÁLISE DOS EFEITOS DE MEDIDAS ANTIDUMPING NO SETOR CALÇADISTA BRASILEIRO CONTRA A CHINA
}

\author{
William Reck Dutra ${ }^{1}$, Rafael Poerschke², Samia Mercado Alvarenga ${ }^{3}$
}

\begin{abstract}
Resumo: $\mathrm{O}$ presente artigo pretende analisar os efeitos da medida antidumping tomada pelo Brasil contra as importações advindas do setor calçadista chinês. A adoção desse mecanismo de defesa comercial, caso seja efetivo, pode produzir tanto um efeito destruição de comércio quanto um efeito criação de comércio. Nesse sentido, o objetivo do presente artigo é demonstrar se houve benefícios ao setor calçadista nacional e de que maneira a medida afetou a composição do mercado de calçados no país. Pretende-se atingir esse propósito através de uma análise empírica que emprega uma adaptação do modelo sugerido por Anderson e Thuresson (2008) amparada por uma revisão bibliográfica. Os dados utilizados se referem ao setor calçadista brasileiro e foram coletados a partir da base disponibilizada pelo Ministério do Desenvolvimento, Indústria e Comércio. A análise abrange desde o período anterior a medida até o seu término. Os principais resultados constatam a influência estatística da taxa de câmbio e da renda nas importaçóes de calçados brasileiras e atestam que os calçados provenientes da China ambos os efeitos esperados, ou seja, a medida antidumping acarretou destruição de comércio, bem como desvio de comércio. De um modo geral, tais achados apontam para uma modificação na composiçáo concorrencial do segmento calçadista sugerindo a efetividade da política comercial brasileira no combate ao dumping praticado pela China no seguimento de calçados.
\end{abstract}

Palavras-chave: Dumping. Antidumping. Setor calçadista. Comércio internacional. Brasil. China.

Abstract: This article analyzes the effects of the anti-dumping measure against imports from Brazil of Chinese
footwear. The adoption of this trade defence mechanism, should be effective, can produce an effect so much
destruction of trade as trade creation effect. In this sense, the objective of this article is to demonstrate whether
there were benefits to the national footwear and that way the measure affected the composition of the footwear
market in the country. It is intended to achieve this purpose through an empirical analysis that employs an
adaptation of the model proposed by Anderson and Thuresson (2008) supported by a literature review. The data

1 Graduado em Ciências Econômicas pelo Centro Universitário Franciscano (UNIFRA-RS). E-mail: Williamreckdutra@gmail.com

2 Doutorando do Programa de Pós-Graduação em Estudos Estratégicos Internacionais da Universidade Federal do Rio Grande do Sul (UFRGS). Mestre em Economia pela Universidade do Vale do Rio dos Sinos (Unisinos). Economista, Bacharel em Ciências Econômicas pela Universidade Federal de Santa Maria (UFSM). Especialista em Estatística e Modelagem Quantitativa pela UFSM. Mestre em Integração LatinoAmericana pela UFSM. Atualmente atua como professor assistente no Centro Universitário Franciscano (UNIFRA) E-mail: rafael.poerschke@unifra.br

3 Mestranda do Programa de Pós Graduação em Economia da Universidade Federal de Sergipe (UFS). Graduada em Ciências Econômicas pela Universidade Federal de Santa Maria (UFSM-RS) E-mail: samia_alvarenga@hotmail.com 
used relate to the Brazilian footwear and were collected from the base provided by the Ministry of development, industry and trade. The analysis covers since the period before the measure until your termination. The main results confirm the statistical influence of the exchange rate and income on imports of Brazilian footwear and attest that footwear from China both expected effects, that is, the antidumping measure entailed the destruction of trade as well as trade diversion. In general, these findings point to a change in the competitive composition of the footwear segment, suggesting the effectiveness of the Brazilian commercial policy in the fight against the dumping practiced by China in the follow-up of footwear.

Keywords: Dumping. Anti-dumping. Footwear. International trade. Brasil. China.

\section{INTRODUÇÁO}

A produção calçadista é um dos setores mais tradicionais e consolidados no Brasil (SUZIGAN, 1986). Entretanto por ser intensivo em mão-de-obra sofreu mudanças a partir da década de 90 com a abertura comercial especialmente devido às ameaças competitivas de países que operam a baixo custo, como é o caso da China (COSTA, 2000; SCHREIBER, 2015). Nesse sentido, a abertura comercial brasileira, aliada a valorização do câmbio decorrente da estabilização de preços (1994), fez com que o setor passasse por um período de relativas dificuldades, principalmente no que diz respeito ao mercado interno.

Desse modo, para proteger as indústrias domesticas, o processo de abertura comercial passou caracterizar-se pela aplicação de barreiras temporárias, tais como o antidumping medida que visa combater a prática desleal de comércio por uma empresa que, buscando dominar o mercado de um país estrangeiro, exporta seu produto para esse país a um preço abaixo do considerado justo durante um período de tempo, visando prejudicar ou eliminar a concorrência (PRUSA, 1996). Esse período ficou mundialmente conhecido como "novo protecionismo" (BHAGWATI, 1988). No Brasil, a primeira década dos anos 2000 evidencia essa realidade testemunhando a entrada do país no clube dos principais usuários desse instrumento. Segundo dados do World Bank of Temporary barriers Chad Bown World Bank (2016) as medidas antidumping do Brasil saltaram de 34 entre os anos 2000 a 2004 para 125 entre os anos 2010 a 2015.

Para que as medidas antidumping náo sejam distorcidas e aplicadas de forma arbitrária a Organização Mundial do Comércio (OMC) estabelece como princípios a tipificação, a exclusividade, a objetividade e não cumulação. Desse modo, para que sejam legítimas, as medidas antidumping não podem ser concomitante a outras medidas e devem deter-se a neutralização ou impedimento do dumping enquadrado no Artigo VI do Acordo Geral sobre Tarifas e Comercio (GATT) que dispóe sobre o fato, o dano e o nexo causal em simultâneo (SENA JÚNIOR, 2003).

Apesar da Organizaçáo Mundial do Comércio (OMC) legislar sobre o antidumping, pratica inicialmente adotada para proteger indústrias nacionais de práticas predatórias de indústrias estrangeiras, ele vem sendo largamente utilizado de forma indiscriminada por diversas naçóes. De acordo com Prusa (2001), as medidas antidumping aumentaram em todos os países não porque cresceu a competição desleal, e sim por uma popularização do seu uso para barrar a concorrência externa. Entre as consequências de sua aplicação o autor destaca o efeito destruição de comércio, quando reduz o fluxo de importação do país citado, 
e o efeito desvio de comércio, quando essa redução de importações é complementada pelo aumento do fluxo comercial com novos participantes.

Diante disso, para trata do impacto das medidas antidumping adotadas pelo Brasil contra as importaçóes de calçados da China durante o período de 2010 a 2015, o presente artigo adapta à realidade brasileira o modelo sugerido por Anderson e Thuresson (2008). Ao utilizar o modelo outrora sugerido por Anderson e Thuresson (2008), intenciona-se preencher uma lacuna na literatura nacional sobre o comércio do setor de calçados cobertos por medidas antidumping.

Procura-se assim, responder se a imposição de antidumping pode ser considerada eficiente, e qual é seu impacto no fluxo comercial de calçados do Brasil com a China e o resto do mundo? No intuito de elucidar essa questão, para dar respaldo a posterior aplicação empírica, primeiramente faz-se uma leitura breve da evolução do antidumping no comércio internacional, bem como da experiência brasileira.

Por conseguinte, testa-se a hipótese do surgimento dos efeitos destruição de comércio e desvio de comércio no país quando a medida antidumping contra o setor calçadista chinês foi julgada e, depois, efetivada. Espera-se que a aplicação da medida antidumping pelo Brasil contra as importaçóes chinesas gere um o efeito destruição de comércio, ou seja, que o fluxo de importação de calçados da China diminua, ao passo que os valores subam. Ainda, como critério de avaliação da efetividade da política, espera-se que o efeito desvio de comércio seja positivo.

\section{REFERENCIAL TEÓRICO}

A produção de calçados, segundo Costa (2002), é caracterizada por um processo discreto, uma tecnologia de fácil acesso e economias de escala não muito expressivas. Além disso, o setor possui composição heterógena variando conforme o processo a natureza do produto. Brasil, China e Coréia do Sul possuem um setor de grandes empresas, enquanto na Itália, Espanha e Taiwan predominam empresas de pequenas unidades produtivas. Esses fatores aliados a baixas barreiras de entrada possibilitam que a indústria se desenvolva em diferentes regióes e países (COSTA, 2004).

No Brasil a manufatura de calçados é tão antiga quanto tradicional, tendo seu início no Rio Grande Sul, a partir de uma indústria local de pequena escala que ganhou força após 1870 quando máquina de costura adentra a regiâo. Embora ainda se mantivessem propriedades caracteristicamente artesanais é nesse período que a produção de calçados se torna dinâmica e passa a acontecer também dentro das fabricas (SUZIGAN, 1986).

No período posterior, entre 1920 e 1960, o setor vivencia estagnação devido à intensa regionalização da produção e ausência de inovaçóes, inclusive por parte das grandes empresas (CORREA, 2001). Mesmo com um cenário pessimista, a produção de calçados ganha importância na pauta de exportaçóes nacional fomentando a implantação de máquinas, equipamentos e artefatos na região Sul. Os avanços tecnológicos da década de 70 foram seguidos, na década seguinte, por melhorias organizacionais e operacionais, tais como controle da qualidade e da produção, bem como planejamento e introdução de tecnologias inovadoras (CORREA, 2001). 
Ainda hoje, o Rio Grande Sul, se mantém como a principal região produtora de calçados, entretanto existem empresas em diversos estados brasileiros como, por exemplo, Minas Gerais, São Paulo, Santa Cataria e Ceará. O nordeste ingressou no circuito calçadista ao final dos anos 90 em razão dos subsídios fiscais que deslocaram para essa região parte da produção que antes se concentrava no Sul do país. Para Costa (2004), o processo produtivo do calçado geralmente se compóe de mão de obra não dependente de qualificaçóes especiais, o que o coloca no perfil de indústrias, que diante do processo de globalização, tiveram seu eixo transferido para países menos desenvolvidos como a China, Taiwan e Brasil. Esse panorama somado a internacionalização da produção que o Brasil vivenciava desde o final dos anos de 1960, beneficiou o setor por já possuir um mercado local consolidado sendo praticamente autossuficiente no atendimento ao público doméstico (MDIC, 2016).

Todavia, a abertura comercial brasileira intensificada nos anos 90, somadas a valorização do câmbio decorrente da estabilização de preços (1994), trouxe um período de relativas dificuldades ao setor (CORRÊA, 2001). No que diz respeito ao mercado interno, enquanto não foi adotado um câmbio flutuante, o produto de origem estrangeira conseguiu realizar uma concorrência relevante, alcançando, segundo dados do MDCI (2016), uma média de 200 milhóes de dólares no triênio 1995-97 caindo para uma quarta parte desse valor em 1999, quando o câmbio flutuante se efetivara.

Houve ainda aumento na procura por calçados esportivos e de material sintético, que não são a especialidade brasileira haja vista que seu ponto forte é a fabricação de sapatos de couro. Ante a esse contexto desfavorável e frente à baixa taxa de crescimento da demanda, o governo adotou, em meados de 1995, um programa de apoio para combater essas dificuldades. Dentre as atitudes tomadas destacam-se a linha de crédito emergencial e medidas de salvaguardas através da com a introdução de alíquotas aos calçados importados (COSTA; FLIGENSPAN, 1997).

A principal preocupação nesse período de instabilidade do setor calçadista foi com a concorrência dos calçados fabricados pela China e revendidos no Brasil. A produção calçadista Chinesa possui uma base competitiva semelhante à brasileira, ou seja, mãode-obra disponível a custo baixo (SCHREIBER, 2015). Conforme Schreiber (2015), os aumentos das exportaçóes por parte da China indicavam a existência da prática de dumping, que segundo resolução da Organização Mundial do Comercio (OMC) é definido como venda de uma mercadoria abaixo de seu preço de custo comparável.

Em outras palavras, o dumping é prática comercial considerada desleal que se dá quando o país exportador intenciona debelar a concorrência para conquistar posição dominante via preços frente aos competidores. Dessa forma, o preço de exportação do bem de consumo exportado do país praticante de dumping é menor que o preço no decurso das operaçôes comerciais para bens similares destinados ao consumo no país de exportação (GATT/OMC, 1995).

Outro indício de dumping é a prática de preços médio inferior à média dos demais competidores. Ambos os panoramas são evidenciados nas Tabelas 1 e 2 . A primeira tabela mostra as importaçóes de calçados em milhóes de pares durante os anos de 1999 até 2008, ano em que o Brasil, diante da suspeita de dumping chinês no setor calçadista, faz a petição 
antidumping. Já a segunda tabela demonstra o preço médio das importaçóes por pares de calçados entre 1999 a 2015.

Tabela 1 - Importaçóes brasileiras de calçados vindos dos principais produtores mundiais (Milhões de pares/participação entre 1999-2008)

\begin{tabular}{|c|c|c|c|c|c|c|c|c|c|c|}
\hline \multirow{3}{*}{ País } & \multirow{2}{*}{\multicolumn{4}{|c|}{ Período pré- investigação }} & \multicolumn{5}{|c|}{ Investigaçáo do Dano à Indústria } & \multirow{3}{*}{$\begin{array}{c}\text { Petiçáa* } \\
2008 \\
\end{array}$} \\
\hline & & & & & \multirow{2}{*}{\begin{tabular}{|c|} 
P I \\
2003 \\
\end{tabular}} & \multirow{2}{*}{\begin{tabular}{|c|} 
P II \\
2004 \\
\end{tabular}} & \multirow{2}{*}{\begin{tabular}{|l|} 
P III \\
2005 \\
\end{tabular}} & \multirow{2}{*}{\begin{tabular}{|l|} 
P IV \\
2006
\end{tabular}} & \multirow{2}{*}{$\begin{array}{c}\text { P V } \\
2007\end{array}$} & \\
\hline & 1999 & 2000 & 2001 & 2002 & & & & & & \\
\hline China & 3,25 & 3,15 & 3,25 & 3,42 & 3,83 & 7,14 & 13,64 & 14,44 & 24,24 & 33,18 \\
\hline$(\%)$ & 34,5 & 37,2 & 34,9 & 40,8 & 42,8 & 45,2 & 45,0 & 44,1 & 46,1 & 46,1 \\
\hline Indonésia & 1,17 & 0,55 & 0,40 & 0,27 & 0,24 & 0,38 & 0,56 & 0,62 & 0,79 & 1,03 \\
\hline$(\%)$ & 12,5 & 6,5 & 4,3 & 3,2 & 2,7 & 2,4 & 1,9 & 1,9 & 1,5 & 1,4 \\
\hline Itália & 0,12 & 0,09 & 0,42 & 0,09 & 0,08 & 0,05 & 0,06 & 0,07 & 0,06 & 0,07 \\
\hline$(\%)$ & 1,2 & 1,0 & 4,5 & 1,0 & 0,8 & 0,3 & 0,2 & 0,2 & 0,1 & 0,1 \\
\hline Tailândia & 0,17 & 0,27 & 0,39 & 0,19 & 0,04 & 0,05 & 0,27 & 0,21 & 0,16 & 0,22 \\
\hline$(\%)$ & 1,8 & 3,2 & 4,2 & 2,3 & 0,4 & 0,3 & 0,9 & 0,7 & 0,3 & 0,3 \\
\hline Vietná & 0,38 & 0,37 & 0,29 & 0,25 & 0,32 & 0,33 & 1,14 & 1,95 & 2,01 & 3,21 \\
\hline$(\%)$ & 4,0 & 4,4 & 3,1 & 3,0 & 3,6 & 2,1 & 3,8 & 6,0 & 3,8 & 4,5 \\
\hline Outros & 4,32 & 4,03 & 4,58 & 4,18 & 4,44 & 7,83 & 14,66 & 15,45 & 25,29 & 34,29 \\
\hline$(\%)$ & 45,9 & 47,6 & 49,0 & 49,7 & 49,6 & 49,6 & 48,3 & 47,2 & 48,1 & 47,6 \\
\hline $\begin{array}{l}\text { Total } \\
\text { res de sapatos) }\end{array}$ & 9,41 & 8,45 & 9,33 & 8,40 & 8,95 & 15,7 & 30,33 & 32,75 & 52,56 & 72,01 \\
\hline
\end{tabular}

Fonte: Elaborada com base nos dados fornecidos pelo MDIC (2016).

* Pedido de medida antidumping contra a China pelo Brasil.

Tabela 2 - Preço médio de importação brasileiras de calçados vindos da China, Vietnam, Itália e Portugal (por par de calçado 1999-2015)*

\begin{tabular}{r|r|r|r|r|r}
\hline \multirow{2}{*}{ Ano } & \multicolumn{7}{c}{ País } \\
\cline { 2 - 6 } & \multicolumn{1}{|c|}{ China } & \multicolumn{1}{c}{ Vietnam } & \multicolumn{1}{c}{ Itália } & \multicolumn{1}{c}{ Portugal } & Preço Médio \\
\hline $\mathbf{1 9 9 9}$ & 4,81 & 10,09 & 13,24 & 14,30 & 11,90 \\
\hline $\mathbf{2 0 0 0}$ & 6,03 & 13,67 & 22,22 & 8,67 & 1,39 \\
\hline $\mathbf{2 0 0 1}$ & 5,40 & 13,58 & 16,74 & 16,32 & 7,86 \\
\hline $\mathbf{2 0 0 2}$ & 7,48 & 15,90 & 28,08 & 18,48 & 8,07 \\
\hline $\mathbf{2 0 0 3}$ & 7,98 & 15,24 & 33,08 & 19,44 & 8,28 \\
\hline $\mathbf{2 0 0 4}$ & 6,40 & 14,51 & 52,77 & 24,14 & 8,95 \\
\hline $\mathbf{2 0 0 5}$ & 5,76 & 15,15 & 57,99 & 19,12 & 9,24 \\
\hline $\mathbf{2 0 0 6}$ & 6,08 & 15,79 & 79,93 & 20,35 & 7,49 \\
\hline $\mathbf{2 0 0 7}$ & 6,13 & 14,55 & 140,70 & 29,18 & 6,88 \\
\hline $\mathbf{2 0 0 8}$ & 6,56 & 14,65 & 115,49 & 27,14 & 7,64 \\
\hline $\mathbf{2 0 0 9}$ & 8,18 & 15,81 & 105,80 & 26,65 & 7,36 \\
\hline
\end{tabular}




\begin{tabular}{r|r|r|r|r|r}
\hline \multirow{2}{*}{ Ano } & \multicolumn{6}{|c}{ País } \\
\cline { 2 - 6 } & \multicolumn{1}{|c|}{ China } & \multicolumn{1}{c}{ Vietnam } & \multicolumn{1}{c}{ Itália } & \multicolumn{1}{c}{ Portugal } & \multicolumn{1}{c}{ Preço Médio } \\
\hline $\mathbf{2 0 1 0}$ & 6,25 & 17,48 & 167,01 & 27,79 & 7,87 \\
\hline $\mathbf{2 0 1 1}$ & 6,96 & 17,60 & 158,92 & 31,99 & 9,81 \\
\hline $\mathbf{2 0 1 2}$ & 5,66 & 18,87 & 171,44 & 34,20 & 11,02 \\
\hline $\mathbf{2 0 1 3}$ & 6,19 & 17,84 & 136,52 & 38,28 & 12,97 \\
\hline $\mathbf{2 0 1 4}$ & 7,01 & 17,51 & 153,70 & 36,51 & 14,59 \\
\hline $\mathbf{2 0 1 5}$ & 7,23 & 17,46 & 13,89 & 29,22 & 14,75 \\
\hline
\end{tabular}

Fonte: Elaborado com base nos dados fornecidos pelo MDIC (2016). * - Valores nominais em US\$/FOB.

Conforme a Tabela 1 percebe-se que as importaçóes de calçados chineses, em especial a partir de 2004, praticamente dobrou tornando-se, em 2008, quase metade das importaçóes nacionais totais. A partir da Tabela 2 pode-se reconhecer um preço médio do calçado chinês inferior à média dos outros principais exportadores que competem no mercado brasileiro. Tanto a Tabela 1 quanto a Tabela 2 dáo indícios da prática de dumping por parte da China.

Para assegurar um mercado global mais livre, ocasionalmente são empreendidos esforços que culminam com a projeçáo de medidas temporárias com intuito de limitar a concorrência desleal no comércio internacional. Assim, os países signatários da OMC acordaram quanto à utilização do antidumping como mecanismo válido para corrigir distorçôes ocasionadas pelas práticas desleais, caso estas suscitem danos à indústria doméstica do país receptor do produto. Apesar das posiçôes contrárias, tais como a do Reino Unido, que consideraram essa decisão prejudicial à liberalização comercial, o Código Antidumping do GATT entrou em vigor em 1968 (BARBOSA, 2007).

Segundo Carvalho e Araújo (2008), as medidas antidumping consistem em uma taxa, cujo valor náo deve exceder à margem de dumping. Dessa forma a taxa seria o preço normal subtraído do preço de exportação. Sendo que este é o preço efetivamente pago pelo Brasil, sem impostos e à vista, enquanto aquele é o valor a vista, sem incluir impostos, cobrado no país exportador por um produto similar ao exportado, em volume significativo nas operaçóes que a empresa aufere lucro. Nesse sentido, se as vendas no mercado interno do exportador representar pelo menos 5\% do volume exportado para o país isso também pode demonstrar um dumping específico contra ele.

Conforme Porter (1990), quando aplicadas, as medidas antidumping favorecem a proteção de um ou mais setores produtivos da economia, a justificativa para seu emprego encontra respaldo na existência de assimetrias competitivas. Todavia, a falta de clareza sobre quando elas devem ser tomadas abre precedente para seu uso indiscriminado, especialmente por setores com influência política, o que contraria a concorrência saudável do comércio internacional, pois segundo a teoria das vantagens comparativas de David Ricardo, dois países se favorecem mutuamente quando comercializam entre si o que produzem de maneira mais eficiente (PRUSA, 2001).

De acordo com o raciocínio por trás da abertura cada vez maior do comércio internacional, está o pressuposto de que as mercadorias sejam ofertadas por quem possa produzi-las mais eficientemente, de modo que a proteção arbitrária de determinada 
indústria torne-se um ônus para o resto dos participantes (PORTER, 1990). A exemplo disso um país que proíba a importaçáo de determinado produto em favor de uma empresa nacional menos eficiente faria com que os residentes tivessem que consumir um produto mais caro, ou de menor qualidade, contrariamente ao que consumiria caso pudesse optar pelo estrangeiro (PORTER, 1990). No Brasil, para evitar eventuais pressôes políticas decorrentes da abertura comercial, foram promulgados acordos antidumping, assim como subsídios e direitos compensatórios.

Todavia, ainda que as medidas antidumping sejam o principal mecanismo de barreira comercial utilizado no mundo, o Brasil no inicio dos anos 2000 utilizava esse instrumento de maneira ponderada se comparado a países como EUA, Índia e UE (KUME; PIANI, 2004). Uma década depois, conforme dados da OMC (2014), o país aplicou 32 medidas antidumping representando quase $20 \%$ de um total de 157 medidas aplicadas pelos países da OMC. Esse número colocou o país na posição maior aplicador do instrumento no ano de 2014, seguido por Estados Unidos (22) e Índia (15).

As medidas antidumping, por atuarem como instrumentos de política comercial, provocam diversos efeitos quando postas em prática. Dois deles, em particular interessam ao presente artigo. O primeiro o feito destruição de comércio que ocorre quando diminuem os fluxos de importaçóes do produto do país atingido pela medida, podendo reduzir ainda as importaçóes de outros produtos desse mesmo país.

O segundo é efeito desvio de comércio que acontece igualmente quando as exportações do país atingido pela medida antidumping diminuem no país que executou a medida sendo que paralelamente há um aumento da importaçáo do produto ou similar vindo de países que antes não estavam presentes no circuito competitivo, substituindo as importações do país afetado pela medida (VINER, 1950). Neste caso, o efeito é considerado positivo uma vez que aumenta a concorrência tornando-se um dos argumentos mais persuasivos para a aplicação de uma medida antidumping.

O comércio do Brasil com a China no setor calçadista é ilustrado no Gráfico 1, segundo o qual pode-se constatar que no período pré-investigaçáo da medida antidumping (1999 a 2002), assim como período posterior (2002 a 2008) a investigação, não houve queda na compra de calçados estrangeiros, havendo verdadeiramente, uma tendência de crescimento no que se refere a quantidade de pares de sapato. 
Gráfico 1 - Importações brasileiras de Calçados Chineses (1999-2015 em número de pares)*

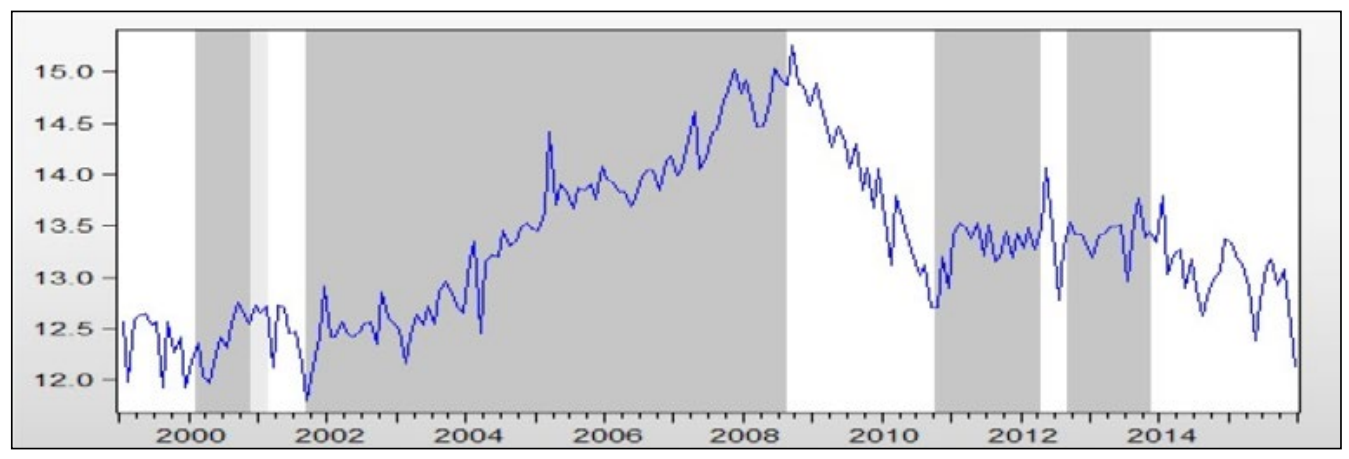

Fonte: Elaborado com base nos dados fornecidos pelo MDIC (2016).

*Dados em logaritmos.

O Gráfico 1 revela em cinza os ciclos de alta das importaçóes brasileiras que ao todo foram quatro, o mais longo deles, com quase 38 meses antecede a abertura da investigaçáo no ano de 2008. Após a imposição da medida é possível notar a reversão deste ciclo de alta, isto é, as importaçóes chinesas começam a recuar dando sinais do efeito destruição de comércio. Na Tabela 3 é demonstrado o total de pares de calçados importados pelo Brasil, bem como a porcentagem da participação de cada país nas importaçôes de calçados entre os anos de 1999 a 2015.

Tabela 3 - Importações de pares ${ }^{4}$ de calçados e participação entre 1999-2015

\begin{tabular}{c|r|r|r|r|r|r|r|r|r|r}
\hline \multirow{2}{*}{ País } & \multicolumn{10}{c}{ Estágios do caso China-Brasil } \\
\cline { 2 - 12 } & \multicolumn{1}{c|}{ Pré } & Dano & Petiçáo & Abertura & \multicolumn{7}{|c}{ Vigência do direito Antiduming } \\
\cline { 2 - 12 } & $\mathbf{1 9 9 9 -}$ & $\mathbf{2 0 0 3 -}$ & $\mathbf{2 0 0 8}$ & $\mathbf{2 0 0 9}$ & $\mathbf{2 0 1 0}$ & $\mathbf{2 0 1 1}$ & $\mathbf{2 0 1 2}$ & $\mathbf{2 0 1 3}$ & $\mathbf{2 0 1 4}$ & $\mathbf{2 0 1 5}$ \\
\hline China & 3,27 & 12,66 & 33,18 & 22,37 & 8,37 & 9,62 & 10,25 & 9,57 & 7,49 & 6,29 \\
\hline (\%) & 32,8 & 44,6 & 46,1 & 42,7 & 23,5 & 22,9 & 23,0 & 19,9 & 17,0 & 16,0 \\
\hline Indonésia & - & - & 1,03 & 1,81 & 3,63 & 5,55 & 5,91 & 7,03 & 6,61 & 6,50 \\
\hline (\%) & - & - & 1,4 & 3,5 & 10,2 & 13,2 & 13,3 & 14,6 & 15,0 & 16,5 \\
\hline Itália & 0,18 & 0,06 & 0,07 & 0,08 & 0,05 & 0,08 & 0,08 & 0,14 & 0,14 & 0,14 \\
\hline (\%) & 1,9 & 0,33 & 0,1 & 0,1 & 0,1 & 0,2 & 0,2 & 0,3 & 0,3 & 2,9 \\
\hline Tailândia & 0,32 & 1,15 & 0,22 & 0,08 & 0,04 & 0,05 & 0,27 & 0,21 & 0,16 & 0,22 \\
\hline (\%) & 3,5 & 3,9 & 0,3 & 0,1 & 0,6 & 0,8 & 1,3 & 1,4 & 1,1 & 1,4 \\
\hline Vietnáy & 0,32 & 1,15 & 3,21 & 4,08 & 7,35 & 10,43 & 14,95 & 16,74 & 18,47 & 14,92 \\
\hline (\%) & 3,6 & 3,9 & 4,5 & 7,8 & 20,7 & 24,8 & 33,6 & 34,8 & 42,0 & 38,0 \\
\hline Camboja & - & - & - & 0,02 & 0,04 & 0,13 & 0,25 & 1,59 & 0,63 & 0,94 \\
\hline (\%) & - & - & - & 0,0 & 0,01 & 0,3 & 0,6 & 3,3 & 1,4 & 2,4 \\
\hline
\end{tabular}

4 Em milhões de pares. 


\begin{tabular}{|c|c|c|c|c|c|c|c|c|c|c|}
\hline \multirow{3}{*}{ País } & \multicolumn{10}{|c|}{ Estágios do caso China-Brasil } \\
\hline & \multirow{2}{*}{$\begin{array}{c}\text { Pré } \\
1999- \\
2002 \\
\end{array}$} & \multirow{2}{*}{$\begin{array}{c}\text { Dano } \\
2003- \\
2007 \\
\end{array}$} & \multirow{2}{*}{\begin{tabular}{|c|} 
Petiçáo \\
2008 \\
\end{tabular}} & \multirow{2}{*}{\begin{tabular}{|c|} 
Abertura \\
2009 \\
\end{tabular}} & \multicolumn{6}{|c|}{ Vigência do direito Antiduming } \\
\hline & & & & & 2010 & 2011 & 2012 & 2013 & 2014 & 2015 \\
\hline Portugal & & & 0,01 & 0,01 & 0,00 & 0,02 & 0,04 & 0,04 & 0,03 & 0,03 \\
\hline$(\%)$ & -1 & - & 0,0 & 0,0 & 0,0 & 0,1 & 0,3 & 0,3 & 0,3 & 0,3 \\
\hline Outros & 4,28 & 13,53 & 34,29 & 23,99 & 15,91 & 15,87 & 12,48 & 12,26 & 10,13 & 8,95 \\
\hline$(\%)$ & 48,08 & 48,57 & 47,6 & 45,8 & 44,7 & 33,7 & 28,8 & 25,5 & 23,0 & 22,8 \\
\hline Total & 8,90 & 13,53 & 72,02 & 52,43 & 35,55 & 42,05 & 44,53 & 48,06 & 44,00 & 39,92 \\
\hline
\end{tabular}

Fonte: Elaborado com base nos dados fornecidos pelo MDIC (2016).

A partir da Tabela 3 é possível prognosticar quanto ao efeito desvio de comércio, uma vez que há tendência de aumento tanto na porcentagem de participação quanto no número total de calçados chineses no mercado nacional, chegando a compor $46 \%$ das importaçóes totais em 2008. Após a vigência das medidas antidumping, sua participação nas importações decresceu para $16 \%$ do total. Por outro lado, países, como o Vietná, que antes eram menos expressivos entraram com mais força no mercado nacional, ocupando o espaço que a China perdeu com a vigência das medidas. $\mathrm{O}$ que denota, preliminarmente, um efeito desvio de comércio.

Braga e Silber (1993) identificaram, no caso específico do Brasil, benefícios decorrentes do desvio de comércio após a imposição do antidumping. Baran (2015), através de dados do Global Antidumping Database (GAD) mantido por Chad Bown junto ao Banco Mundial, demonstrou que existe a presença de um significativo efeito destruição do comércio quando a medida é definitivamente imposta.

Esse efeito seria progressivo durante o período analisado, passando, por exemplo, de uma queda de $21 \%$ no primeiro ano para $37 \%$ no segundo (GAD, 2015). O estudo de Baran (2015) indica, ainda, que o efeito, embora exista, é menor quando as investigaçóes são encerradas sem sua efetiva aplicação. Isso porque, as importaçôes foram sujeitas a um antidumping provisório, tendo um efeito pequeno e restrito ao período de aplicaçáo da medida. Já para o efeito de desvio de comércio, mesmo sendo estaticamente significativo, as "imports from non-named countries outside the EU rises in the third and fifth year after initiation" (BARAN, 2015, p.11).

Estudos dessa natureza também foram desenvolvidos por Andersson e Thuresson (2008) que verificaram as consequências do antidumping da Uniáo Europeia contra China no setor calçadista. Segundo os autores, o comércio de calçados chineses com a UE caiu $84 \%$ durante o período de vigência da medida, mesmo diante de um aumento no comércio de calçados como um todo na regiáo. O que caracteriza um grande impacto do antidumping no comércio do referido setor. Outros estudos, tais como o de Maques (2002) e Tavares (2006) tratam das consequências do antidumping aplicado ao comércio de aço, suco de laranja, por exemplo, contudo, carecem no Brasil, estudos relativos ao setor calçadista que teve sua importância relevante na balança comercial das últimas décadas. 


\section{METODOLOGIA}

A fim de testar os efeitos de medidas antidumping do setor calçadista nacional contra as importaçóes chinesas, este artigo apresenta uma análise quantitativa embasada na aplicação empírica do modelo sugerido por Anderson e Thuresson (2008) que utilizam Mínimos Quadrados Ordinários (MQO), com variáveis logaritmizadas, conforme Equação 1 :

$$
\begin{aligned}
& \mathrm{M}=\beta_{1}+\beta_{2} \mathrm{t}+\beta_{3} \mathrm{DD}+\beta_{4} \mathrm{AD}+\beta_{5} \mathrm{E}+\beta_{6} \mathrm{MM}+\beta_{7} \mathrm{Y}+\mathrm{u}_{\mathrm{t}} \\
& \text { Onde: } \\
& \mathrm{M}=\text { importação de calçados; } \\
& \beta_{1}=\text { constante; } \\
& \beta_{2}=\text { parâmetro relacionado ao tempo; } \\
& \beta_{3}=\text { parâmetro associado com o período de investigação do antidumping; } \\
& \beta_{4}=\text { parâmetro associado com o período de aplicaçáo do antidumping; } \\
& \beta_{5}=\text { parâmetro para a taxa de câmbio; } \\
& \beta_{6}=\text { parâmetro referente ao desvio de comércio; } \\
& \beta_{7}=\text { parâmetro referente a renda. }
\end{aligned}
$$

Tal modelo, originalmente empregado para o caso dos calçados na Europa, foi adaptado às necessidades da presente pesquisa com o intuito de averiguar os efeitos da medida antidumping do setor calçadista nacional contra a China (seja o efeito destruição de comércio ou o efeito desvio de comércio, caso tenham de fato ocorrido).

Umas das propriedades do modelo de Anderson e Thuresson (2008) reside na mensuração da taxa de crescimento ou decréscimo das importações através da análise do vetor tendência T. Assim, uma variação relativa em T, aplicado o exponencial, demonstra a taxa de crescimento (ou decrescimento) para uma mudança absoluta nas importaçóes. Sendo essa variável um vetor tendência, seu sinal apontará para uma tendência ascendente caso seja positivo e descendente caso seja negativo.

Ressalta-se aqui utilização de duas variáveis Dummies, uma para o período referente à investigação da medida antidumping (DD) e outra para ao período em que a medida é efetivada $(\mathrm{AD})$. Para a primeira o valor 1 corresponde ao período de investigação da medida, enquanto o valor 0 corresponde ao período de efetivação. Já para a segunda os valores são tomados em ordem inversa. O emprego das variáveis Dummies busca captar efeitos desses diferentes períodos no comércio do setor, uma vez que tanto o país que procura adotar a medida antidumping quanto o país que pode ser atingido por ela, tendem a adotar meios de adaptação ao novo cenário de concorrência.

Uma das consequências adaptativas pode ser efeito destruição de comércio o qual será investigado a partir da construção de uma variável instrumental. Para tanto, serão utilizados dados da importação total de calçados pelo Brasil da importação específica de calçados chineses, ambos de janeiro de 1989 até dezembro de 2015. Outra consequência é o efeito 
desvio de comércio que será igualmente verificado, contudo, utilizando dados de janeiro de 1999 até dezembro de 2015, referentes à importação brasileira de calçados vietnamitas e indonésios, dois dos principais exportadores de calçados para o Brasil depois da China. Neste sentido as variáveis empregadas, todas dessazonalizadas, bem como suas respectivas descriçóes, esperança dos sinais e fontes estão representados no Quadro 1.

Quadro 1 - Variáveis que compóe o estudo

\begin{tabular}{|c|c|c|c|}
\hline Variáveis & Descriçáo & Sinal Esperado & Fonte \\
\hline $\mathbf{M}$ & $\begin{array}{c}\text { Importação de calçados } \\
\text { chineses pelo Brasil }\end{array}$ & XXX & Aliceweb (MDIC) \\
\hline $\mathrm{C}$ & Constante & $\mathrm{XXX}$ & XXX \\
\hline $\mathbf{T}$ & Vetor tendência & $\mathrm{XXX}$ & XXX \\
\hline DD & $\begin{array}{l}\text { Dummy que abrange o } \\
\text { período de investigação } \\
\text { da medida antidumping }\end{array}$ & Negativo & $\begin{array}{l}\text { Baseado na Circular no } 95 \text { da } \\
\text { CAMEX } \\
\text { 29/12/2008 até 05/03/2010 }\end{array}$ \\
\hline $\mathrm{AD}$ & $\begin{array}{l}\text { Dummy que abrange o } \\
\text { período da aplicação da } \\
\text { medida antidumping }\end{array}$ & Negativo & $\begin{array}{l}\text { Baseado na resoluçáo no } 14 \\
\text { da CAMEX } \\
05 / 03 / 2010 \text { até } 12 / 12 / 2015\end{array}$ \\
\hline $\mathbf{E}$ & $\begin{array}{l}\text { Taxa de câmbio efetiva } \\
\text { real para a preparaçáo } \\
\text { de couro e calçados }\end{array}$ & Negativo & IPEA \\
\hline LSALR & Salário real & Positivo & IPEA \\
\hline LVIET & $\begin{array}{c}\text { Importaçáo de calçados } \\
\text { vietnamitas }\end{array}$ & Positivo & $\begin{array}{c}\text { Aliceweb (MDIC) } \\
(01 / 01 / 1999 \text { até12/12/2015) }\end{array}$ \\
\hline LINDO & $\begin{array}{c}\text { Importação de calçados } \\
\text { indonésios }\end{array}$ & Positivo & $\begin{array}{c}\text { Aliceweb (MDIC) } \\
(01 / 01 / 1999 \text { até } \\
12 / 12 / 2015) \\
\end{array}$ \\
\hline LMUNDO_SA & $\begin{array}{l}\text { Importação brasileira } \\
\text { de calçados do resto do } \\
\text { mundo }\end{array}$ & Positivo & $\begin{array}{c}\text { Aliceweb (MDIC) } \\
(01 / 01 / 1999 \text { até } \\
12 / 12 / 2015) \\
\end{array}$ \\
\hline
\end{tabular}

Fonte: Elaborado pelos autores.

Sobreleva-se que todos os produtos estão classificados entre os códigos 6402 a $6405^{5}$ da resoluçáo no14 da CAMEX, de 14/03/2010, a qual efetivou a aplicaçáo da medida antidumping. O parâmetro relativo à taxa de câmbio efetiva real do setor calçadista foi utilizado tendo em vista que oscilaçóes no valor do Real tendem a influenciar de maneira distinta o comércio do setor. Uma apreciaçấo cambial, ou seja, um aumento no valor da moeda doméstica, pode conduzir a um aumento da exportação ou uma diminuição da importação, um efeito contrário é observado frente a uma depreciação cambial.

5 Segundo a Nomenclatura Comum do Mercosul (NCM) nas posiçóes 6402 a 6405 estão inseridos os artefatos para proteção dos pés, voltados para o público masculino, feminino ou infantil, destinados ao uso diário social ou esportivo, construídos com a parte superior e inferior em material natural ou sintético. 


\section{RESULTADOS E DISCUSSÓES}

$\mathrm{Na}$ Tabela 4 são exibidos os modelos estimados com a finalidade de selecionar as variáveis adequadas à investigação dos efeitos decorrentes das medidas antidumping contra a China.

Tabela 4 - Resultados dos modelos escolhidos

\begin{tabular}{|c|c|c|c|c|}
\hline Variáveis & Modelo 1 & Modelo 2 & Modelo 3 & Modelo 4 \\
\hline C & $\begin{array}{c}6,746225^{* *} \\
(0,0421) \\
\end{array}$ & $\begin{array}{c}8,052252^{* *} \\
(0,0151)\end{array}$ & $\begin{array}{c}4,090442^{* * *} \\
(0,1373) \\
\end{array}$ & $\begin{array}{c}3,714053^{* * *} \\
(0,1800) \\
\end{array}$ \\
\hline $\mathbf{T}$ & $\begin{array}{c}0,013255^{*} \\
(0,0000)\end{array}$ & $\begin{array}{c}0,013584^{*} \\
(0,0000)\end{array}$ & $\begin{array}{c}0,004751^{*} \\
(0,0025)\end{array}$ & $\begin{array}{c}0,004076^{*} \\
(0,0032)\end{array}$ \\
\hline DD & $\begin{array}{c}-0,733815^{* *} \\
(0,0303) \\
\end{array}$ & $\begin{array}{c}-0,651101^{* * *} \\
(0,0593) \\
\end{array}$ & $\begin{array}{c}-0,243867^{* * *} \\
(0,3368) \\
\end{array}$ & $x$ s \\
\hline $\mathrm{AD}$ & $\begin{array}{c}-1,896079^{*} \\
(0,0000)\end{array}$ & $\begin{array}{c}-1,835941^{*} \\
(0,0000)\end{array}$ & $\begin{array}{c}-0,577469^{* *} \\
(0,0158)\end{array}$ & $\begin{array}{c}-0,427903^{* *} \\
(0,0157)\end{array}$ \\
\hline LE_SA & $\begin{array}{c}-1,094830^{*} \\
(0,0001) \\
\end{array}$ & $\begin{array}{c}-1,189790^{*} \\
(0,0000) \\
\end{array}$ & $\begin{array}{c}-0,544638^{* *} \\
(0,0208)\end{array}$ & $\begin{array}{c}-0,475762^{* *} \\
(0,0441) \\
\end{array}$ \\
\hline LSALR & $\begin{array}{c}2,785194^{*} \\
(0,0000) \\
\end{array}$ & $\begin{array}{c}2,737011^{*} \\
(0,0000) \\
\end{array}$ & $\begin{array}{c}0,897668^{* * *} \\
(0,0667) \\
\end{array}$ & $\begin{array}{c}0,889592^{* * *} \\
(0,0742)\end{array}$ \\
\hline LINDO & $\begin{array}{c}-0,119046^{* *} \\
(0,0224) \\
\end{array}$ & - & 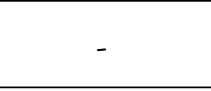 & - \\
\hline LNMUNDO_SA & - & $\begin{array}{c}-0,181943^{* * *} \\
(0,0527) \\
\end{array}$ & $\begin{array}{c}-0,095109^{* * *} \\
(0,1477) \\
\end{array}$ & $\begin{array}{c}-0,123037^{* *} \\
(0,0404) \\
\end{array}$ \\
\hline LM_SA(-1) & - & - & $\begin{array}{c}0,650023^{*} \\
(0,0000) \\
\end{array}$ & $\begin{array}{c}0,684407^{*} \\
(0,0000) \\
\end{array}$ \\
\hline $\mathbf{R}^{2}$ & 0,794386 & 0,795975 & 0,871734 & 0,869305 \\
\hline Durbin-Watson & 1,046992 & 1,029874 & 2,307247 & 2,318372 \\
\hline
\end{tabular}

Fonte: Elaborado pelos autores.

Nota: Desvio-padrão entre parênteses; $\left({ }^{*}\right)$ indica a rejeição a $1 \%,\left({ }^{* *}\right)$ a $5 \%$ e a $\left({ }^{* *}\right) 10 \%$.

Observa-se que, conforme Tabela 4, no modelo 1, foram utilizadas as duas dummies, uma relativa ao período de investigação (DD), que compreende o período de 29/12/2008 até 05/03/2010, e a outra referente a efetivação do antidumping (AD), que vai de 05/03/2015 até 12/12/2015. O modelo também considerava a variável correspondente à taxa de câmbio real efetiva para a produção de couro e calçados (LE_SA), uma proxy para renda, representada pelo salário real (LSALR) e as importaçôes de calçados indonésios (LINDO). $\mathrm{O} \mathrm{R}^{2}$ confere um poder explicativo de aproximadamente $80 \%$ ao Modelo 1, porém, a autocorrelação de 1,046992, atestada no teste Durbin-Watson, usado para verificar a existência de autocorrelação dos resíduos, ou seja, a presença de correlação entre as observações, indica que o erro não é aleatório, o que contradiz os pressupostos da modelagem linear e conduz a estimação de novos modelos na tentativa de eliminar esse problema.

O segundo modelo é bastante semelhante ao primeiro, contudo, procurando encontrar uma representação mais clara do efeito desvio de comércio, ao invés das exportaçóes de calçados indonésios utilizam-se as exportaçóes de calçados do mundo como um todo. A 
autocorrelaçâo se mantém, assim como o poder explicativo do Modelo 2 que segue com um $\mathrm{R}^{2}$ próximo a $80 \%$. Para corrigir o problema de autocorrelação foi incluída no terceiro modelo, a exemplo do modelo original de Anderson e Thuresson (2008), uma variável defasada relativa aos salários. Como resultado obteve-se um modelo com maior capacidade explicativa (87\%) e o problema de autocorrelação finalmente foi resolvido. Entretanto, o Modelo 4 com um $\mathrm{R}^{2}$ elevado e uma ausência de autocorrelação foi o que se mostrou mais condizente.

Conforme os resultados da Tabela 5 para o Modelo 1, o vetor tendência mostrou, a um nível de confiança de aproximadamente 97\%, que as importações originárias da China cresceram, em média, 1,33\% ao mês. Ambas as dummies tiveram sinal negativo ${ }^{6}$, coerente com o esperado, já que tanto durante a investigação quanto durante a aplicação de medidas definitivas antidumping as importaçóes vindas do país que, possivelmente, terá medidas aplicadas contra si, tendem a diminuir. Quanto a suas taxas, ao longo do período de investigação, podem ser atribuídos efeitos destruição de comércio com uma queda na média de importação de-51,99\% em relação ao período anterior à investigação.

No período do direito definitivo, os cinco anos de vigência da medida em vigor representam uma destruição de comércio de $-84,98 \%$ que acontece quando a importação de produtos do país sobre o qual é aplicada a medida diminui. A magnitude do coeficiente apesar de parecer elevada se alinha aos resultados de Andersson e Thuresson (2008) que encontraram, durante o período de vigência da medida, uma redução de $84 \%$ do comércio de calçados chineses na EU mesmo que o comércio desse setor tenha aumentando na região durante esse período.

Ainda no que tange ao Modelo 1 e às elasticidades dos outros parâmetros, o coeficiente referente à taxa de câmbio apresentou o sinal negativo conforme o esperado. Isso porque seu aumento causa uma desvalorização da moeda, portanto, diminui o poder de compra no estrangeiro, tornando as importaçóes mais caras. Sua interpretaçáo fornece diretamente a elasticidade, isto é, a cada $1 \%$ de aumento na taxa de câmbio há um decréscimo na demanda de $1,9 \%$. Já a proxy para renda, salário real, reportou um sinal positivo, também esperado, já que o aumento da renda possibilita a compra de mais calçados, tanto dos produtores nacionais quanto dos estrangeiros.

A magnitude desse parâmetro o coloca na categoria de bem superior haja vista que sua demanda é altamente elástica (2,8\%), ou seja, aumentos na renda geram aumentos mais que proporcionais na demanda (VARIAN; REPCHECK, 2010). Partindo para a análise do desvio de comércio, o parâmetro referente às exportaçóes indonésias para o Brasil teve sinal negativo retratando que um aumento nas importaçóes de calçados indonésios tende a ocupar o espaço antes ocupado por concorrentes como a China, atestando a existência de certo desvio da demanda de calçados da China, que são, em parte, substituídas pelas exportações indonésias.

6 A dummy do período da investigaçáo da medida reportou um desvio do real menor que $1 \%$, enquanto a do período de investigaçáo possui um desvio de aproximadamente 3\%. 
No modelo 2, de acordo com a Tabela 5, o vetor tendência seguiu apresentando uma taxa de crescimento, dessa vez um pouco maior que a anterior ( $1,36 \%$ ao mês), já o parâmetro relativo ao período de investigação, teve queda na média de importaçôes mensais diminuída para $47 \%$, revelando um desvio um pouco maior do que $5 \%$, o que embora não seja algo grave, está acima do que se pretende no modelo. Para o período da aplicação definitiva, a taxa mensal manteve-se basicamente no mesmo valor ( $84 \%$ ao mês).

O modelo também confirmou a presença de desvio de comércio, o comportamento da elasticidade se manteve estável mesmo quando a variável explicativa foi alterada dado que nesse modelo utilizaram-se as a soma da importaçáo brasileira de calçados de todo o mundo, com exceção dos chineses ${ }^{7}$. Quanto aos parâmetros relativos ao câmbio e a renda, o primeiro passou de $-1,094830$ para $-1,189790$, enquanto no segundo a elasticidaderenda ${ }^{8}$ de 2,785194 caiu para 2,737011, essas pequenas mudanças não alteraram o nível de confiança aproximado de $100 \%$. Incluída variável defasada relativa aos salários no Modelo 3 o vetor tendência apresenta uma taxa de crescimento menor que nos modelos anteriores (cerca de $0,47 \%$ ao mês). Também houve redução em ambas as dummies cujas médias de vendas caíram em quase a metade se comparadas aos modelos anteriores. No período de investigação passam a aproximadamente $-21 \%$ e no período de aplicação a $-43 \%$.O nível de confiança da dummy do período de investigação mostrou-se menor, aproximadamente $67 \%$. Nesse modelo, as elasticidades-renda apresentaram o positivo, conforme esperado, porém a suas magnitudes colocam os calçados como bens de primeira necessidade, cujas demandas sáo inelásticas, de modo que um aumento na renda de $1 \%$ gera aumento de consumo menor que o proporcional (VARIAN; REPCHECK, 2010).

Por fim, o quarto modelo, reportou para o vetor tendência uma taxa de crescimento de $0,40 \%$ ao mês das importaçóes da China. Como a dummy relativa ao período de investigação perdeu muito do seu nível de confiança, optou-se por deixá-la fora da estimação. Os resultados apresentados no efeito destruição de comércio se mostraram inferiores em mais de $50 \%$ em relação ao modelo original. Já a dummy referente ao período de aplicação de medidas antidumping causou, ao nível de confiança aproximado de $98 \%$, uma redução de $34 \%$ na importação de calçados chineses, um resultado inferior ao dos autores supracitados.

Durante o período de aplicaçáo da medida, o modelo acusou certo desvio de comércio para outras fontes fornecedoras de calçados. Analisando os parâmetros relativos ao câmbio e a renda, ambos tiveram uma pequena queda na elasticidade, isto é, o relativo à taxa de câmbio, recuou para $0,47 \%$ e a elasticidade-renda caiu para $0,88 \%$. Esse resultado sinaliza que as importações brasileiras de calçados são influenciadas pelo crescimento da renda interna.

7 A série de dados com os valores do Vietnam mostrou-se náo significativa em todos os modelos testados.

8 Variaçáo percentual da quantidade demandada resultante do aumento de $1 \%$ na renda. 


\section{CONSIDERAÇÓES FINAIS}

Em virtude do crescimento do uso de medidas antidumping de comércio no mundo e especialmente no Brasil, o presente trabalho teve como propósito avaliar seus efeitos no setor calçadista Brasileiro contra a China. O estudo buscou elucidar, com base nas teorias do comércio internacional e aplicação do modelo empírico proposto por Anderson e Thuresson (2008), como a imposição de medidas antidumping tende a impactar a China. A partir disso especulou-se, de um lado, acerca da redução do fluxo comercial em decorrência direta do efeito da medida sobre os preços, e, de outro lado, sobre ocupação deste espaço no mercado brasileiro pelos concorrentes não arrolados no processo de investigaçáo. Através da aplicação adaptada do modelo sugerido por Anderson e Thuresson (2008), estas hipóteses foram testadas.

Conforme o modelo 2, houve um efeito destruição de comércio durante o período de investigação, baseado no sinal negativo do parâmetro. Isto significa que o mercado cativo dos calçados chineses importados foi substituído pela indústria doméstica ou de outros países concorrentes. Assim, a política comercial apresenta-se como efetiva em afastar os calçados com dumping, que foram substituídos por outros fornecedores estrangeiros. Neste ponto, isto é um indicador de proteçâo da defesa comercial brasileira contra uma prática reconhecidamente desleal e náo um mecanismo que impede uma concorrência justa, protecionismo.

Em relação ao período de aplicação da medida, houve igualmente um efeito destruição de comércio, com uma taxa de decréscimo de $34 \%$. O sinal dos parâmetros relativos aos dois países selecionados, assim como o referente ao resto do mundo, todos negativos, demonstraram também a existência do efeito desvio de comércio, outro resultado esperado pelas medidas. Ainda podem-se mencionar os efeitos tanto da taxa de câmbio quanto do nível de renda sobre o setor durante o período. No modelo original proposto pelos autores supracitados, estas variáveis não eram explicitas e, para dados do Brasil, as mesmas foram utilizadas e significativas. Assim, as importaçóes de calçados no Brasil são igualmente sensíveis ao câmbio e ao aumento do nível de renda da população.

Por fim, resultados estimados, de modo geral, mostraram a ocorrência de efeitos reais nesse setor, tanto de destruiçấo quanto de desvio de comércio, demonstrando que as medidas tomadas pelo Brasil obtiveram o resultado esperado, modificando a composiçáo desse segmento, com um crescimento tanto dos competidores nacionais quanto de outros países participantes. É válido ressaltar que conforme a resoluçáo no 20 da CAMEX, de $1^{\circ}$ de março de 2016, houve uma prorrogação por mais cinco anos dessas medidas, deixando espaço para mais estudos acerca de efeitos vindouros no setor calçadista nacional.

\section{REFERÊNCIAS}

ABICALÇADOS. Associação Brasileira de Calçados. Relatório Anual 2001. Novo Hamburgo. 2015.

ABICALÇADOS. Associação Brasileira de Calçados. Relatório Anual 2015. Novo Hamburgo. 2015. 
THURESSON, Carin; ANDERSSON, Karolina. The Impact of an Anti-dumping Measure: A Study on EU Imports of Chinese Footwear. Jönköping 2008.

BHAGWATI, Jagdish N. Protectionism. MIT press, 1989.

BARAN, Jan et al. The impact of antidumping on EU trade. IBS Policy Paper, v. 12, p. 2015, 2015.

BARBOSA, Alexandre Englert. Impacto da Área de Livre Comércio das Américas (ALCA) e potencial antidumping. 2007.

BRASIL. Circular n. 95 da Câmara de Comércio Exterior - CAMEX/MDIC - 29 de dezembro de 2008. Diário Oficial, Brasília. Publicada no D.O.U. de 31 de dezembro de 2008.

BRASIL. Resolução n. 14 da Câmara de Comércio Exterior - CAMEX/MDIC - 04 de março de 2010. Diário Oficial, Brasília. Publicada no D.O.U. de 05 de março de 2010.

CARVALHO, Rosemeiry Melo; ARAÚJO, Rochele Alves de. Vantagens comparativas e desempenho das exportaçóes do setor pesqueiro brasileiro no mercado norte-americano. In: Congresso da Sociedade Brasileira de Economia, Administração e Sociologia Rural - SOBER, 2008.

CORRÊA, Abidack Raposo. O complexo coureiro-calçadista brasileiro. Bndes Setorial, v. 14, 2001.

COSTA, Achyles B. da; FLIGENSPAN, Flávio B. Avaliação do movimento de relocalização industrial de empresas de calçados do Vale do Sinos. Porto Alegre: Sebrae, 1997.

COSTA, A. B. Inovações e mudanças na organização industrial. Ensaios FEE, v. 21, n² 2, p. 7-31, 2000.

COSTA, AB da. Estudo da Competitividade de Cadeias Integradas no Brasil: impactos das zonas de livre comércio. Cadeia: Couro e Calçados. Nota técnica final. Convênio: MDIC/MCT/FINEP/NEIT (IE/UNICAMP). Campinas/SP: dezembro, 2002.

DA COSTA, Achyles Barcelos; PASSOS, Maria Cristina. A indústria calçadista no Rio Grande do Sul. Editora Unisinos, 2004.

KUME, Honorio; PIANI, Guida. Regime antidumping: a experiência brasileira. 2004.

MARQUES, Maria Silvia Bastos. Restrições ao aço nos EUA: lições de hipocrisia. Valor Econômico, Sáo Paulo, p. A-10, v. 8, 2002. 
MINISTÉRIO DO DESENVOLVIMENTO, INDÚSTRIA E COMÉRCIO

EXTERIOR - MDIC. Balança Comercial Brasileira. Disponível em: http://www.

desenvolvimento.gov.br//sitio/sistema/balanca/. Acesso em: 19 abr. 2016.

PORTER, Michael E. The competitive advantage of nations. 1990.

PRUSA, Thomas J. The trade effects of US antidumping actions. National Bureau of Economic Research, 1996.

PRUSA, Thomas J. On the spread and impact of anti-dumping. Canadian Journal of Economics/Revue canadienne d'économique, v. 34, n. 3, p. 591-611, 2001.

SCHREIBER, Dusan. ANÁLISE REFLEXIVA DA CULTURA ORGANIZACIONAL SUBJACENTE À INOVAÇÃO NAS INDÚSTRIAS DE CALÇADOS. Perspectivas Contemporâneas, v. 10, n. 3, p. 103-125, 2015.

SENA JÚNIOR, Roberto Di. Comércio internacional \& globalizaçáo: a cláusula social na OMC. Juruá, 2003.

SUZIGAN, Wilson. A indústria brasileira em 1985/86: desempenho e política. Carneiro, R. op. cit, 1986.

TAVARES, Maria Flávia de Figueiredo. O mercado futuro de suco de laranja concentrado e congelado: um enfoque analítico. 2006.

VARIAN, Hal R.; REPCHECK, Jack. Intermediate microeconomics: a modern approach. New York: WW Norton \& Company, 2010.

VINER, Jacob. The Customs Union Issue. Carnegie Endowment for International Peace. New York, 1950. 